\title{
SEMANTILISED ROLLID KEELEUURIMISE VAHENDINA
}

\author{
Liina Lindström ja Piia Taremaa \\ Tartu Ülikool
}

Kokkuvõte. Semantilised rollid väljendavad semantilisi suhteid entiteetide ja sündmuste vahel ning on keeleteaduses laialt kasutatav vahend lause predikaadi ja tema argumentide omavaheliste suhete selgitamiseks semantilisel tasandil. Sellegipoolest ei ole keeleteaduses välja kujunenud ühest arusaama sellest, kui palju ja millised semantilised rollid on keele kirjeldamisel vajalikud. Käesolevas artiklis tutvustatakse olulisemat semantiliste rollidega seotud problemaatikat. Artiklis antakse ülevaade semantiliste rollide ajaloost, enamkasutatavatest semantilistest rollidest, rollide hierarhilisusest ning rolle eristavatest olulistest joontest (kontroll, mõjutatus, elusus), rollide markeerimisest ja kuhjumisest eesti keele näidete varal.

Märksõnad: semantilised rollid, temaatilised rollid, rollihierarhiad, kontroll, mõjutatus, elusus, eesti keel

\section{Sissejuhatuseks}

Semantilised rollid kirjeldavad tähendusest lähtudes suhteid lauses väljendatud entiteetide ja sündmuse vahel. See on keeleteaduses laialt kasutatav vahend lause elementide omavaheliste suhete selgitamiseks semantilisel tasandil, võimaldades kirjeldada semantika ja süntaksi seoseid. Hoolimata laiast kasutusest ei ole keeleteaduses välja kujunenud ühest arusaama sellest, millised semantilised rollid on keele kirjeldamisel vajalikud, kas need on universaalsed või pigem keelespetsiifilised, või kui palju semantilisi rolle on vajalik eristada ühe keele või keelenähtuse kirjeldamiseks. Siiski on semantilised rollid leidnud keeleteaduses palju kasutust selle uurimisel, kuidas lausega väljendatud sündmuste osalisi (grammatiliselt) markeeritakse, keeletüpoloogias ning mujalgi.

Semantiliste rollide määratlemiseks alustatakse sündmusest, mida tüüpiliselt väljendatakse verbiga, ning muid sündmu- 
ses osalejaid (mida tavaliselt väljendatakse nimisõna(fraaside)ga) mõistetakse selle sündmuse kaudu. Kõneleja valib seega sobiva verbi ning sellega sobivad osaliste rollid ning kodeerib need vastavalt konkreetse keele morfosüntaktilistele vahenditele. Oluline on seejuures kõneleja vaatepunkt, kuidas ta sündmust kujutada soovib. Näiteks lauses (1) on poiss AGENT (tegevuse tahtlik sooritaja), aken PATSIENT (tema seisund muutub sündmuse tõttu), kivi aga VAHEND (ehk INSTRUMENT). Lauses (2) on kivi kujutatud sündmuse põhjustajana, st akna lõhkujana (JõUD või PÕHJUSTAJA), mida võib käsitleda ka INSTRUMENDINA eeldusel, et kivi on visanud poiss akna lõhkumise eesmärgil. Igal juhul ei saa kivi ise elutu objektina toimida tahtlikult, st AGENDINA.

(1) Poiss lõhkus kiviga akna.

(2) Kivi lõhkus akna.

Ka (3) ja (4) on näited sellest, kuidas sama sündmust võib kujutada erinevalt. Lauses (3) on selga kujutatud конАNA ning kreemi PATSIENDINA, lauses (4) aga selga PATSIENDINA ning kreemi VAHENDINA. Selline vaheldus on keeleteaduses tuntud kui kohavaheldus (locative alternation).

(3) Ema määris selja peale kreemi.

(4) Ema määris selga kreemiga.

Semantilised rollid ei ole seega midagi keelevälist, vaid need selguvad konkreetses lauses ning sõltuvad sellest, kuidas keelekasutaja sündmust kujutab. Samas on keelte vahel suuri erinevusi, kuidas rolle on võimalik kodeerida (nt mis käändes üks või teine roll võib olla), millised rollid võivad esineda süntaktiliste subjektide ja objektidena, millised piirangud neil on jne.

Semantilised rollid on eri lähenemistes kandnud eri nimetusi. Nii on kasutatud termineid käändesuhted (case relationships), käänded (cases) või süvakäänded (deep cases) (vt nt Fillmore 1968, 1971, 2003), temaatilised suhted (thematic relations) või ka semantilised suhted (semantic relations) (vt nt Gruber 1965, Jackendoff 1972, 1983), temaatilised rollid (vt nt 
Frawley 1992), $\Theta$-rollid (teeta-rollid) generatiivses traditsioonis (vt nt Chomsky 1993 [1981], 1996 [1995]), argumendirollid (argument roles) konstruktsioonigrammatikas (vt nt Goldberg 1995), temaatilised suhted rolli ja referentsi grammatikas (Van Valin 2001, 2005, Van Valin ja LaPolla 2004). Siinses käsitluses jääme termini semantilised rollid juurde eelkõige seetõttu, et see on mainitutest kõige teoorianeutraalsem ja kõige laialdasemalt kasutuses.

Artikli eesmärk on anda eesti lugejale lühike ülevaade semantiliste rollide ajaloost, rollide määratlemise problemaatikast ning rollide markeerimisest ja kuhjumisest eesti näidete varal. Selle taustal püüab artikkel anda vastuse kahele omavahel seotud küsimusele: miks semantilisi rolle vaja on ning kuidas semantilisi rolle on võimalik keeleuurimisel kasutada.

\section{Semantiliste rollide ajaloost}

Semantiliste rollide käsitlused on välja kasvanud generatiivse transformatsioonigrammatika täiustamise vajadusest. Generatiivne transformatsiooniteooria oma algsel kujul semantikat ei hõlmanud (Chomsky 1957). Gruberi väitekirjast „Studies in lexical relations" (1965) tõukudes arendasid nii Fillmore kui ka Jackendoff generatiivset grammatikat nii, et sellega oleks hõlmatud ka semantiline aspekt.

1967. aastal esitas Fillmore sümpoosiumil „Universals in Linguistic Theory” (ning aasta hiljem artiklis „The Case for Case") oma nägemuse, kuidas transformatsioonigrammatikat edasi arendada. Fillmore'i käsitluses kandsid semantilised rollid käände või käändesuhete, ka süvakäänete nimetust. Käändena mõistis Fillmore „semantiliselt relevantseid süntaktilisi suhteid, mis hõlmavad substantiive ning neid sisaldavaid struktuure" (Fillmore 1968: 5). Fillmore tõi varasemast traditsioonist erinevalt esile seda, et käändesuhted ei ole üks-üheses vastavuses grammatiliste suhetega, vaid et sama kääne võib süntaktiliselt avalduda mitmel moel. Esialgu esitles Fillmore kuut käänet (mööndes samas, et nimekiri pole lõplik), hiljem ta käsitlus 
täiustus. Kui algselt Fillmore (1968: 21) välistas rollide kuhjumise (vt ptk 5), siis hilisemates käsitlustes sõnab Fillmore (1971, 2003), et vahel on võimalik ka rollide koosesinemine.

Jackendoff esitas oma käsitluse 1972. aastal teoses „Semantic Interpretation in Generative Grammar”. Erinevalt Fillmore'ist väidab Jackendoff enda (ja Gruberi) käsitluse eeliseks olevat just selle, et süntaks ja semantika on lahutatud (Jackendoff 1972: xi) ning nimisõnafraasid võivad olla seotud mitme temaatilise rolliga (Jackendoff 1972: 34-43). Jackendoff käsitleb viit Gruberi temaatilist suhet, lisades neile veel teisesed temaatilised suhted (secondary thematic relations), kuna just need määravad erinevused verbitähenduste vahel, sest sel viisil saavad temaatilised suhted kombineeruda (1972: 29-36). Ühena esimestest pakub Jackendoff ka välja ühe temaatiliste suhete hierarhia (1972: 43-46) (hierarhiatest vt ptk 3.2).

Edasi levis semantiliste rollide kasutus mitmes suunas, saavutades sellise iseseisvuse, et sageli kasutatakse konkreetseid semantilisi rolle keelematerjali analüüsimisel üldnimedena semantiliste rollide terminile ning vastavatele käsitlustele viitamata. Tüpoloogilistes uurimustes kasutatakse semantilisi rolle võrdlemaks argumentide markeerimist sarnastes sündmustes paljudes eri keeltes, st võrdlemaks sama rolli avaldumist eri keeltes (vt nt Zúñiga ja Kittilä, toim. 2010). Samuti analüüsitakse semantiliste rollide hierarhiaid ning nende võimalikku universaalsust (see vaatenurk avaldub eriti süstemaatiliselt rolli ja referentsi grammatikas (vt ptk 6)). Oma iseseisev ning teistsugune roll ja tähendus on semantilistel rollidel generatiivse grammatika traditsioonis, kus neid kasutatakse transformatsioonireeglitele semantilise mõõtme andmiseks (vt nt Chomsky 1993 [1981], 1996 [1995]). Semantilised rollid on osaliselt ka taustaks Langackeri trajektorile ja orientiirile kognitiivses grammatikas (Langacker 1987) ning Talmy kujundile ja taustale kognitiivses semantikas (Talmy 2000a, 2000b) - Dowty (1991) nimetab trajektorit ja orientiiri ning kujundit ja tausta koguni semantiliste rollide kandidaatideks -, samuti on semantilistel rollidel oluline osa konstruktsioonigrammatika käsitlustes (vt nt Goldberg 1995). 
Teoreetilise raamistiku erinevustest ning uurimiseesmärkide paljususest tulenevalt ühtne käsitlus semantiliste rollide osas puudub. Lõpliku nimekirja postuleerimist üldiselt välditakse, kuna alati on võimalik veel mõnede rollide määratlemise vajalikkus, teisalt on ka eriarvamused semantiliste rollide defineerimise osas. Teisalt oleks hea, kui semantilised rollid oleks võimalikult konventsionaalsed, võrdlemaks erinevaid keeleuurimusi.

\section{Semantiliste rollide määratlemisest}

Semantilisi rolle on määratletud nii puhtsemantilistena (nii et ideaaljuhul oleks semantiliste rollide olemasolu täiesti sõltumatu sellest, kas vastavat situatsiooni keeleliselt väljendatakse või mitte (vt nt Payne 2006: 105; 2007: 47)) kui ka millegi sellisena, mis on süntaksi ja semantika vahepeal, ühendades neid omavahel. Traditsiooniliselt on esimese näiteks peetud Jackendoffi (vt nt 1972, 1983) ning teise näiteks Fillmore'i käsitlusi (vt nt Fillmore 1968, 1971, 2003). Järgnevalt läheneme semantiliste rollide määratlemisele kolmest vaatenurgast, mis tegelikult on kõik omavahel seotud: esiteks, kui detailselt semantilisi rolle eristada ning millised on tavalisemad kasutatavad semantilised rollid; teiseks, kas käsitleda semantilisi rolle ühe- või mitmetasandilise nähtusena; kolmandaks, milliste omaduste alusel semantilisi rolle üldse eristada.

\subsection{Semantiliste rollide eristamise detailsus ning enamkasutatavad semantilised rollid}

Predikaat väljendab mingit situatsioonitüüpi ning ühtlasi määrab semantilised rollid, ehk viisid, kuidas sellises situatsioonis osaleda saab (vt nt Andrews 2007 [1985]: 132, 135). Ent semantiliste rollide defineerimisel on teatav annus arbitraarsust: semantilisi rolle püütakse defineerida sel moel, et nende abil oleks võimalikult hea mõista keelenähtusi (Andrews 2007 [1985]: 137). Semantiliste rollide sisu defineerimise osas 
on üksjagu eriarvamusi, nagu on ka eri käsitlusi selles osas, kui detailselt semantilisi rolle määratleda. On käsitlusi, kus peetakse semantilisteks rollideks nii spetsiifilisi verbikeskseid rolle, nagu näiteks 'tapja' ja 'tapetav' verbi tapma korral kui ka palju abstraktsemaid rolle nagu AGENT ja PATSIENT (vt nt Andrews 2007 [1985]). Teistes käsitlustes peetakse sellist detailset käsitlust liiaseks ning räägitakse üksnes üldistest semantilistest rollidest nagu viimatinimetatud (vt nt Fillmore 1968, 1971, 2003). Nii rõhutab Fillmore, et pole mõtet eristada väga konkreetseid ühest verbist tulenevaid käändesuhteid, vaid vaja on taoliste spetsiifiliste rollide abstraktsioone, kuna sel moel on võimalik leida eri situatsioonide ühisjooned (1971: 376). Üldjoontes võib aga öelda, et semantilised rollid, nende arv ja sisu on sõltuvuses sellest, milline on uurimiseesmärk, mistõttu ei olegi ilmselt võimalik ühtne ja täielik semantiliste rollide loend.

Järgnevalt nimekiri enamkasutatavatest semantilistest rollidest ja nende definitsioonidest mõningate autorite näitel ${ }^{1}$.

AGENT (agent): sündmuse algataja (Fillmore ${ }^{2}$, Van Valin ja LaPolla), tüüpiliselt elusolend (Payne); see, kes midagi teeb või põhjustab ning seda (ilmselt) tahtlikult (Andrews, Gruber, Jackendoff, Payne); sündmuse kontrollija, kes viib tegevuse läbi sel moel, et sel on silmaganähtavad tulemused (Payne); eesmärgipärane ja tahtlik tegutseja (Van Valin ja LaPolla). Nt Poiss lükkab käru.

AUTOR (author): agendilaadne osaleja, kes pole sündmuse otsene põhjustaja (Frawley; sageli sellist rolli ei eristata). Nt Pall lükkas vaasi ümber.

1 Eestikeelse põhjaliku ülevaate Frawley (1992) käsitletavatest semantilistest rollidest leiab Renate Pajusalu õpikust „Sõna ja tähendus“ (2009: 81-88). Liikumissündmusega seotud semantiliste rollidega seonduvast problemaatikast saab ülevaate artiklist „Lausesemantikast üldkeeleteaduse ja eesti keele kontekstis“ (Õim jt 2010).

2 Lühiduse huvides on siinse rolliloendi juures märgitud viidetena vaid autorinimed. Vastavad pikad viited on: Andrews 2007 [1985]: 135-140, Fillmore 1968: 24-25, 1971: 376, 2003: 151, Frawley 1992:197-249, Gruber 1965 (Jackendoff 1972 kaudu), Jackendoff 1972: 29-34, Payne 2007 [1997]: 47-51, 2006: 104-111, Van Valin ja LaPolla 2004: 85-86. 
JÕUD (force), PÕHJUSTAJA (causer): sündmuse mittetahtlik algataja (Andrews, Payne); mittemanipuleeritav instrumendi-

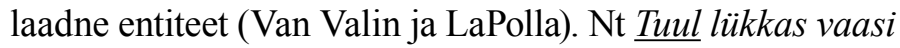
ümber.

PATSIENT (patient): osaleja, kellega/millega midagi juhtub ning kes/mis on sellest mõjutatud (Andrews, Jackendoff); see, kes/mis agendi tegevuse tulemusel teeb läbi mingi muutuse, kelle/mille seisund muutub (Fillmore, Payne); entiteet, $\mathrm{kes} / \mathrm{mis}$ on mingis seisundis või seisundimuutuses (Van Valin ja LaPolla). Nt Poiss lõhkus vaasi. Tüdruk on haige (Van Valin ja LaPolla).

TEEMA (theme), OBJEKT (object, Fillmore): asukohta vahetav entiteet (Frawley, Payne); mingis seisundis või asendis olev või seisundit või asendit muutev osaleja (Andrews); kuskil asetsev või liikuv entiteet (Valin ja LaPolla); liikuv või muutuv või asetsev entiteet (Fillmore). Nt Poiss lükkas käru.

VAHEND (instrument): sündmuse/tegevuse vahetu põhjustaja (Fillmore, Payne); tegevuse läbiviimise vahend (Frawley); see, mille abil AGENT PATSIENDI osas tegevust läbi viib (Andrews, Van Valin ja LaPolla); tüüpiliselt elutu entiteet (Van Valin ja LaPolla). Nt Poiss lükkas labidaga liiva.

KOGEJA (experiencer): see, keda sündmus sisemiselt mõjutab (Fillmore, Frawley, Payne, Van Valin ja LaPolla); millestki teadlik olija (Jackendoff, Andrews). Nt $\underline{\text { Poisile }}$ meeldib tüdruk.

SAAJA (recipient): mingi liikuva objekti elus sihtkoht (Payne); see, kes midagi saab (Andrews, Frawley, Van Valin ja LaPolla) (vahel käsitletakse ka siнтконаna). Nt Poiss annab labida tüdrukule.

(ASU)Конт (location): sündmuse toimumise asukoht (Fillmore, Van Valin ja LaPolla) (sageli hõlmab ka LÄHTE- ja Sінткона). Nt Poiss lükkab õues käru.

LÄнтЕКонт (source): koht, kust midagi liikuma hakkab (Fillmore); objekt, kust/ mille juurest midagi liikuma hakkab (Andrews, Jackendoff); asukohamuutuse algpunkt (Frawley), mingi sündmuse algpunkt (Van Valin ja LaPolla). Nt Poiss tuli toast. 
SІнтконт (goal): koht või objekt, kuhu poole liikumine toimub (Frawley); tüüpiliselt sündmuse elutu sihtpunkt (Van Valin ja LaPolla). Nt Poiss läheb tuppa.

Keelematerjali analüüsimisel võib olla vajalik eristada ka rolle EESMÄRK (purpose), TULEMUS (result), PÕHJUS (reason), AEG (time), VIIS (manner), OMAJA (possessor), OMAND (possessee), KASUSAAJA (benefactive), KAHJUSAAJA (malefactive), KAASASOLIJA (comitative), SUUND (direction), LIIKUMISTEE (path), STIIMUL (stimulus) jms.

Nagu näha, võivad eri rollide definitsioonid osaliselt kattuda (nt AUTOR ja JõUD) või ühe semantilise rolli definitsiooniga hõlmata ka mõne teise võimaliku rolli, nagu PATSIENT, mis hõlmab ka TEEMA, mistõttu sama entiteeti on võimalik käsitleda mitmeti. Kuna käsitlusi nagu ka uurimiseesmärke on palju ning sageli võetakse enimlevinud semantilisi rolle kui iseenesestmõistetavaid, on hea igal konkreetsel juhul analüüsivahendina kasutatavate semantiliste rollide sisu täpselt määratleda. Payne (2007 [1997]: 51-52) toob välja, et semantilised rollid moodustavad mõistelises ruumis kontiinumi, mistõttu sõltub semantiliste rollide hulk sellest, kui peent eristust nende vahel teha soovitakse. Nii võib teatud sündmuse korral osutuda vajalikuks ainult üks semantiline roll конт kolme (või ka enama) ruumirolli asemel, mõne teise sündmuse kirjeldamiseks ei pruugi aga eristada näiteks rolle KOGEJA või SAAJA.

\subsection{Semantilised rollid - ühe- või mitmetasandi- line nähtus?}

Semantiliste rollide detailsuse küsimus on lahendatud käsitlustes, mis vaatlevad rolle mitmetasandilisena (nt Jackendoff 1972, Foley and Van Valin 1984, Dowty 1991, Van Valin 2001, 2005, Lehmann 2006, Næss 2007 jne). Kui näiteks Fillmore (1968, 1971, 2003) ja Frawley (1992) vaatlevad semantilisi rolle ühetasandiliselt (st kirjeldavad üksnes rida rolle nagu esitatud eelnevas peatükiski), siis sageli on keelematerjal paremini analüüsitav lähenedes semantilistele rollidele kui hierarhilisele nähtusele, nii 
et rolle saab eristada mitmel üldistustasandil. Dowty (1991) sõnab näiteks, et semantilised rollid ei ole diskreetsed üksused, vaid nad on prototüüpsemad ja vähemprototüüpsemad, käsitledes näiteks proto-rolle proto-agenti ja proto-patsienti, millest on tuletatavad teised rollid, mis tüüpiliselt subjekti või objekti kujul avalduvad. Goldberg (1995: 43-66) aga kasutab semantilisi rolle kahatasandiliselt, rääkides osalejarollidest (ehk nn freimispetsiifilistest rollidest), mis seostuvad predikaadiga (verbiga) ning argumendi- (ehk semantilistest) rollidest, mis seostuvad konstruktsiooniga.

Järgnevalt peatume hierarhilise käsitluse näitena pikemalt rolli ja referentsi grammatikal (RRG), mille põhiautoriks on Van Valin.

Van Valini $(2001,2005)$ järgi on semantilised rollid eristatavad kolmel üldistusastmel: verbispetsiifilised semantilised rollid (Verb-Specific Semantic Roles), mida saab eristada iga verbi puhul eraldi (nt rollid 'mõtleja', 'uskuja', 'kõneleja', 'lõhkuja', 'lõhutav' jne), temaatilised suhted (Thematic Relations, nt KOGEJA, AGENT, PATSIENT jne; meie käsitluses need on semantilised rollid) ja üldistatud semantilised rollid ehk makrorollid tegija (actor) ja alluja (undergoer). Mida suurem on rollide üldisuse aste, seda enam on rollidevaheline eristus neutraliseerunud, st seda vähem on rollidevahelised semantilised erinevused esil. Seega kõige täpsema eristuse saab teha verbispetsiifiliste rollide tasandil, kõige üldisem on makrorollide tasand, milles aga paljud semantilised vastandused jäävad tähelepanuta.

Võib küsida, miks on makrorollide tasand vajalik? Keeles on võimalik mitmeid erinevaid semantilisi rolle väljendada ühtviisi. Näiteks on võimalik subjektina väljendada nii AGENTI (1), JÕUdU (2), VAHENDIT (5), TEEMAT Või AUTORIT (6), KOGEJAT (7), STIIMULIT (8). Seega peab nende rollide puhul olema mingi ühisosa, mis võimaldab neid suhteliselt erinevaid rolle keeles ühtmoodi kodeerida - teatud hulk semantilisi vastandusi on siin neutraliseerunud. Tegija makrorolli kasutuselevõtt aitab neid kasutusi ühendada ning seda olukorda selgitada.

(5) Traktor kündis põldu.

(6) Pall lendas aknasse. 
(7) Ma armastan musti ploome.

(8) Poissi huvitavad ainult koomiksid.

Ka objektina võivad keeles realiseeruda mitmed erinevad semantilised rollid, kõige tüüpilisemalt on selleks PATSIENT ( põldu näites 3), aga ka näiteks stimul musti ploome (7) või KOGEJA poissi (8). Alluja makrorolli kaudu on võimalik selgitada, miks neid temaatilisi suhteid on võimalik ühtviisi väljendada: neis kõigis on ühine see, et nad on sündmusest mõjutatud.

Kõige prototüüpsem tegija (actor) on AGENT, kõige prototüüpsem alluja (undergoer) on PATSIENT. Van Valin on mõlema rolli puhul välja toonud makrorollide hierarhia: mida rohkem vasakul roll hierarhias paikneb, seda suurema tõenäosusega seda markeeritakse keeltes kui vastavat makrorolli.

\footnotetext{
Tegija hierarhia: AGENT $>$ vAHEND $>$ KOGEJA $>$ SAAJA

Alluja hierarhia: PATSIENT $>$ TEEMA $>$ STIIMUL $>$ KOGEJA $>$ SAAJA/SIHTPUNKT/LÄHTEPUNKT/KOHT
}

Ka makrorollide omavaheline vastandus võib neutraliseeruda. Selle ilminguks on passiivikonstruktsioon, kus alluja on markeeritud subjektina, st samamoodi, nagu tüüpiline tegija (9).

(9) Ma olen kinni seotud.

Seega on RRG-s kasutatud eri tasandi semantilisi rolle selleks, et rollide semantiliste vastanduste neutraliseerumise kaudu osutada, kuidas on semantika ja süntaks omavahel seotud.

\subsection{Semantiliste rollide eristamine: semantiliste rollide omadused}

Semantilistel rollidel on omadused, mille alusel saab rolle eristada, mis teiselt poolt aitab mõista ka rollide markeerimiserinevusi (näiteks miks sama rolli jaoks võib kasutada mitut erinevat käänet). See, millised omadused on teatud keelematerjali 
analüüsimisel olulised, sõltub suuresti uuritavast keelenähtusest ning uurimisküsimusest, mistõttu ei pruugi siinesitatud omadused sugugi ainsad olulised omadused olla, mõnel juhul võivad need omadused osutuda sootuks vähetähtsaks.

Tavaline rollide jaotus põhineb sellel, kui seotud nad sündmusega on, lähtudes eeldusest, et semantilised rollid ei ole kõik võrdsed, vaid nad eristuvad selle põhjal, kui tugevalt nad on sündmusega seotud (involvement). Traditsiooniliselt peetakse näiteks AGENTI ja PATSIENTI sündmusega tugevalt seotud osalejateks ehk keskseteks osalejateks, mis kuuluvad sündmuse tuuma (näites (10) ema ja leiba). N-ö perifeersed rollid (nt VAHEND, KAASASOLIJA, КОНT) reeglina aga sündmuse olemust oluliselt ei mõjuta, nad vaid rikastavad situatsiooni selle põhiolemust oluliselt muutmata (näites (10) köögis ja noaga). (Lehmann 2006)

\section{(10) Ema lõikas (köögis) (noaga) leiba.}

Kesksete osaliste puhul on rollide oluliseks eristajaks ka kontroll (control), mis mõnede autorite meelest on pigem tahtlikkus (volitionality, vt nt Næss 2007), ja mõjutatus (affectedness). Kontroll tähendab osaleja kontrolli situatsiooni üle. Maksimaalsel määral kontrollib sündmust AGENT kui tegevuse teadlik ja tahtlik sooritaja, teistel osalejatel on vähem kontrolli situatsiooni üle. Maksimaalselt mõjutatud osaleja on aga PATSIENT (defineeritud entiteedina, mis situatsiooni käigus muutub, on situatsioonist tugevalt mõjutatud). Näites (10) on ema see osaline, kes kontrollib kogu situatsiooni, ning leib on see osaline, mis on ema tegevusest otseselt mõjutatud ning mille seisund muutub selle tulemusena.

Samas võib aga ka AGENT olla situatsioonist mõjutatud. Sellised on näiteks söömist ja joomist väljendavate predikaatide AGENDID nagu lauses (11): ühelt poolt on ema AGENT, tegevuse teadlik ja tahtlik sooritaja, teiselt poolt on ta aga sündmusest söömise protsessist mõjutatud, st tema seisund muutub söömise käigus. Selliseid agente on nimetatud ka MõJUTATUD AGENTIDEKS (affected agent) (Næss 2007: 52-54).

\section{(11) Ema sõi suhkruleiba.}


Nii seotus sündmusega kui ka kontroll on seotud elususega, mis omakorda on omadus, mille põhjal semantilised rollid varieeruvad (Kittilä jt 2011). Rollid, millega seostuvad eelkõige elusad entiteedid on Kittilä jt järgi (2011: 11) näiteks AGENT, SAAJA, KASUSAAJA, KAHJUSAAJA, KAASASOLIJA, elutute entiteetidega seostuvad aga nende autorite meelest näiteks tüüpiliselt TEEMA, PATSIENT, VAHEND ja КОНT (koos kõigi oma võimalike alltüüpidega). Kõrvalekalded elususe osas võivad väljenduda kahel viisil:

1) vastava rolli kasutus on piiratud vaid elusate või elutute osalejatega,

2) rolli võib kanda nii elus kui elutu osaleja, kuid markeering varieerub sõltuvalt elususest. (Kittilä jt 2011: 11)

Esimese piirangu näitena võib tuua SAAJA rolli, mida tüüpiliselt kannab elus osaleja (Kittilä jt 2011: 11), vrd lapsele ja paadile näidetes (12-13). Näide (13) tundub ilmselt enamikule keelekasutajatest imelik või lausa vastuvõetamatu.

(12) Ema andis lapsele kingituse.

(13) ?Ema andis paadile kingituse.

\section{Semantiliste rollide markeerimine}

Kesksed osalejarollid on keeltes tüüpiliselt markeeritud nö grammatiliste käänetega (eesti keeles näiteks nominatiiv, genitiiv, partitiiv), perifeersed rollid aga pigem obliikvakäänetega (kohakäänded jm) ja kaassõnadega. Näiteks lauses (14) on AGENT ema nimetavas käändes, TEEMA toitu (ehk asukohta muutev entiteet) osastavas käändes, sінтконт lauale aga alaleütlevas (mida võib pidada obliikvakäändeks). Käände asemel võib kasutada ka kaassõnaühendit laua peale.

(14) Ema pani toitu lauale/laua peale.

Seega võib ühe rolli väljendamiseks kasutada erinevaid väljendusvahendeid ning see sõltub lisaks verbi (või konstruktsiooni) omadustele ka mitmetest muudest semantilistest ja prag- 
maatilistest asjaoludest lauses. Eespool mainisime juba elusust, tahtlikkust ja mõjutatust, ent neid tegureid võib olla muidki. (Näiteks eesti keele adessiivi ja kaassõna peal kasutusvahekorda mõjutavate tegurite kohta vt Klavan jt 2010, 2011).

Sõltuvalt keelest aitab rolle eristada ka sõnajärg, selle poolest on eriti tuntud inglise keel. Eesti keeles, kus sõnajärg on suhteliselt vaba, käändeid on palju ning need eristavad keskseid rolle edukalt, on sõnajärjel rollide eristamisel suhteliselt tagasihoidlik osa. Siiski aitab sõnajärg eristada näiteks AGENTI ja PATSIENTI lauses, kus käändeeristus vormihomonüümia tõttu välja ei tule (vt ka Lindström 2004). Kui üldistest maailmateadmistest tulenevat semantilist vastuolu ei teki, tõlgendatakse lauses (15) lausealgulist argumenti AGENDINA, lauselõpulist PATSIENDINA.

(15) Muna õpetab kana.

\section{Semantiliste rollide kuhjumine}

Semantiliste rollide ja süntaktiliste üksuste vaheline suhe ei ole keeles niisiis üks-ühele - nagu on keeles sageli mitu võimalust ühe rolli väljendamiseks (vt ptk 4), nii võib üks keeleline vahend väljendada mitut erinevat rolli. Näiteks on ühtmoodi adessiiviga markeeritud eesti keeles конт (16), OMAJA (17), KOGEJA (18), AEG (19), AGENT (20), viIS (21) jne. On aga lauseid, milles OMAJA on segunenud AGENDIGA, nii et sisuliselt ei ole võimalik eristada, mis roll primaarne on; vaid kontekstist võib selguda, kas üks roll võib osutuda olulisemaks kui teine. Näidetes (20) ja (22) on raske öelda, kas adessiiviga (mul) väljendatakse pigem OMAJAT või AGENTI, tõenäoliselt mõlemat (vt ka Lindström, Tragel 2007).

(16) Laual vedeles hunnik raamatuid.

(17) Mul on suur koer.

(18) Mul on igav.

(19) Hommikul läheb buss Tartusse.

(20) Mul on toad koristatud. 
(21) Ta lähenes meile vaiksel sammul.

(22) Mul olid juuksed soengusse seatud.

Kuigi näidete (20) ja (22) puhul võib agendi roll tuleneda verbidest koristama ja seadma ning omajaroll omajakonstruktsioonist, realiseeruvad nad siiski samal argumendil.

Rollide kuhjumist võime täheldada ka selliste liikumist väljendavate sündmuste puhul, kus liikuja on ühelt poolt tõlgendatav kui AGENT, teiselt poolt aga kui TEEMA (23).

(23) Kusti läks jälle Toome poodi.

\section{Semantilised rollid ja „Eesti keele grammatika”}

„Eesti keele grammatika” (EKG II) ja selle põhjal koostatud „Eesti keele käsiraamat” (EKK) käsitlevad semantilisi rolle kui moodustajate semantilisi funktsioone. Välja on toodud üpris vähe semantilisi funktsioone, ehkki mööndakse, et "olenevalt kirjelduse detailsusest eristatakse rohkem või vähem funktsioone" (EKG II: 11). Välja on toodud vaid rollid, millel on "laiem süntaktiline taust" (EKG II: 11): TEGIJA ehk AGENT, KOGEJA, VALDAJA, NEUTRAALNE OSALINE, VAHEND, KOHT, AEG. EKK (2007) toob neile lisaks välja OMAJA (ja hülgab VALDAJA) ning STIIMULI. Kuna ei EKG-s ega EKK-s ei ole aga semantilise rolle ülejäänud süntaksiosas üldse kasutatud, on rollide napp käsitlus ka selles peatükis mõistetav.

Siiski on EKG-s ja EKK-s kasutatud läbivalt mõisteid tegevussubjekt ja tegevusobjekt. Tegevussubjektiks nimetatakse situatsiooni prominentseimat osalist, mis on ,situatsiooni aktiivseimat osalist tähistav aktant” (EKG II: 12). „Kui lauses on olemas agent, siis talitleb see tegevussubjektina; kui lauses agenti pole, saab tegevussubjektiks kogeja või valdaja; kui ka neid pole, on tegevussubjekt tavaliselt vahend jne" (EKG II: 12). Seega võib EKG käsitluses tegevussubjekti pidada võrreldavaks Van Valini tegija (actor) makrorolliga, tegevusobjekti aga alluja (undergoer) makrorolliga. 


\section{Kokkuvõte}

Siinne artikkel andis ülevaate semantiliste rollidega seotud problemaatikast keeleteaduses: semantiliste rollide mõiste kujunemisest, semantiliste rollide määratlemise võimalustest detailsuse, hierarhilisuse ja rollide omaduste taustal, semantiliste rollide markeerimisest ning kuhjumisest. Hoolimata sellest, et semantiliste rollide hulk varieerub eri käsitlustes suuresti ning ka nende määratlemisel ei ole eri lähenemistes konsensust, on nad siiski keeleteaduses oluline töövahend. Semantiliste rollide abil on võimalik võrrelda keeli omavahel (kuidas on sama semantilist rolli erinevates keeltes väljendatud) ning analüüsida ja võrrelda keelenähtusi ühe keele sees, näiteks selgitada erinevusi käänete ja kaassõnade kasutamisel, kirjeldada mõningate polüseemsete käänete kasutamist, ning üldse seda, kuidas mingi sündmus on keeleliselt väljendatud ning millised semantilised faktorid seda on mõjutanud.

\section{Aadress:}

Liina Lindström ja Piia Taremaa

Eesti ja üldkeeleteaduse instituut

Tartu Ülikool

Jakobi 2, 51014 Tartu

E-mail: Liina.Lindstrom@ut.ee, Piia.Taremaa@ut.ee

\section{Kirjandus}

Andrews, Avery D. (2007) [1985] "The major functions of the noun phrase". Timothy Shopen, ed. Language typology and syntactic description. Vol. 1: Clause structure, 132-223. Cambridge: Cambridge University Press.

Chomsky, Noam (1957). Syntactic structures. The Hague/Paris: Mouton.

Chomsky, Noam (1993) [1981] Lectures on government and binding. Berlin, New York: Mouton de Gruyter.

Chomsky, Noam (1996) [1995] The minimalist program. Cambridge, MA.: The MIT Press.

Dowty, David (1991) “Thematic proto-roles and argument selection.” Language 67, 547-619. 
EKG II = Erelt, Mati, Reet Kasik, Helle Metslang, Henno Rajandi, Kristiina Ross, Henn Saari, Kaja Tael, Silvi Vare (1993) Eesti keele grammatika II. Süntaks. Lisa: kiri. Tallinn: Eesti Teaduste Akadeemia Keele ja Kirjanduse Instituut.

EKK = Erelt, Mati, Tiiu Erelt, Kristiina Ross (2007) Eesti keele käsiraamat. 3., täiend. tr. Tallinn: Eesti Keele Sihtasutus.

Fillmore, Charles J. (1968) “The case for case". In Emmon Bach, Robert T. Harms, eds. Universals in linguistic theory, 1-88. New York: Holt, Rinehart, and Winston.

Fillmore, Charles J. (1971) “Types of lexical information”. In Danny D. Steinberg, Leon A. Jakobovits, eds. Semantics: an interdisciplinary reader in philosophy, linguistics and psychology. Cambridge: Cambridge University Press.

Fillmore, Charles J. (2003) Form and meaning in language. Vol. 1: Papers on semantic roles. Chicago: University of Chicago Press.

Foley, William A., Robert D. Van Valin, Jr. (1984) Functional syntax and universal grammar. Cambridge: Cambridge University Press.

Frawley, William (1992) Linguistic semantics. Hillsdale, New Jersey: Erlbaum.

Goldberg, Adele E. (1995) A construction grammar approach to argument structure. Chicago: University of Chicago Press.

Gruber, Jeffrey (1965) Studies in lexical relations. Cambridge, MA: MIT dissertation.

Jackendoff, Ray (1972) Semantic interpretation in generative grammar. Cambridge, MA: The MIT Press.

Jackendoff, Ray (1983) Semantics and cognition. Cambridge, MA: The MIT Press.

Kittilä, Seppo, Katja Västi, Jussi Ylikoski (2011) "Introduction to case, animacy and semantic roles". In Seppo Kittilä, Katja Västi, Jussi Ylikoski, eds. Case, animacy and semantic roles, 1-26. (Typological Studies in Language, 99.) Amsterdam and Philadelphia: John Benjamins.

Klavan, Jane, Kaisa Kesküla, Laura Ojava (2010) "Eesti keele adessiivi ja kaassõna peal kasutus kahes keelelises katses”. Emakeele Seltsi Aastaraamat 55, 63-86.

Klavan, Jane, Kaisa Kesküla, Laura Ojava (2011) "The division of labour between synonymous locative cases and adpositions: the Estonian adessive and the adposition peal 'on'”. In Seppo Kittilä, Katja Västi, Jussi Ylikoski, eds. Studies on case, animacy and semantic roles, 111-134. Amsterdam: John Benjamins.

Langacker, Ronald W. (1987) Foundations of cognitive grammar. Vol. 1: Theoretical prerequisites. Stanford, California: Stanford University Press.

Lehmann, Christian (2006) "Participant roles, thematic roles and syntactic relations". In Tasaku Tsunoda, Taro Kageyama, eds. Voice and gram- 
matical relations: in honor of Masayoshi Shibatani, 153-174. Amsterdam: John Benjamins.

Lindström, Liina (2004) "Sõnajärg lause tuumargumentide eristajana eesti keeles". Liina Lindström, toim. Lauseliikmeist eesti keeles, 40-49. (Tartu ülikooli eesti keele õppetooli preprindid, 1.) Tartu.

Lindström, Liina, Ilona Tragel (2007) "Eesti keele impersonaali ja seisundipassiivi vahekorrast adessiivargumendi kasutamise põhjal". Keel ja Kirjandus, 7, 532-553.

Næss, Áshild (2007) Prototypical transitivity. Amsterdam: John Benjamins. Pajusalu, Renate (2009) Sõna ja tähendus. Tallinn: Eesti Keele Sihtasutus.

Payne, Thomas E. (2006) Exploring language structure: a student's guide. Cambridge: Cambridge University Press.

Payne, Thomas E. (2007) [1997] Describing morphosyntax: a guide for field linguists. Cambridge, MA: Cambridge University Press.

Talmy, Leonard (2000a) Toward a cognitive semantics. Vol. 1: Concept structuring systems. Cambridge: The MIT Press.

Talmy, Leonard (2000b) Toward a cognitive semantics. Vol. 2: Typology and process in concept structuring. Cambridge, MA: The MIT Press.

Van Valin, Robert D. Jr. (2001) An introduction to syntax. Cambridge: Cambridge University Press.

Van Valin, Robert D. Jr. (2005) Exploring the syntax-semantics interface. Cambridge: Cambridge University Press.

Van Valin, Robert D. Jr., Randy J. LaPolla (2004) Syntax: structure, meaning and function. Cambridge: Cambridge University Press.

Õim, Haldur, Heili Orav, Piia Taremaa (2010) "Lausesemantikast üldkeeleteaduse ja eesti keele kontekstis". Emakeele Seltsi Aastaraamat $55,201-223$.

Zúñiga, Fernando, Seppo Kittilä, eds. (2010) Benefactives and malefactives: typological perspectives and case studies. (Typological Studies in Language, 92.) Amsterdam and Philadelphia: John Benjamins.

\footnotetext{
Abstract. Piia Taremaa and Liina Lindström: Semantic roles as a linguistic tool. Semantic roles are widely used in linguistics to analyse and describe language and are most commonly understand as semantic concepts which show how participants and events are related. However, there is no general agreement about the number of semantic roles; the definitions of semantic roles vary from study to study likewise. In this paper we provide an overview of the history of semantic roles and also give a short list of main semantic roles. Our purpose is to highlight some key aspects of establishing semantic roles, such as narrow vs. wide definitions of semantic roles, the hierarchies of semantic roles, and the main features (namely, control, volitionality, and affectedness) that are related to the content of semantic roles. We
} 
52 Liina Lindström ja Piia Taremaa

also address an issue concerning expressing semantic roles, that is, how a particular semantic role may be lexicalised with different linguistic means and how semantic roles may be conflated.

Keywords: semantic roles, thematic roles, role hieararchies, control, affectedness, animacy, Estonian 